Article

\title{
Evaluation of Complete Pathological Regression after Neoadjuvant Chemotherapy in Triple-Negative Breast Cancer Patients with BRCA1 Founder Mutation Aided Bayesian A/B Testing Approach
}

\author{
Piotr Kedzierawski ${ }^{1,2, *(\mathbb{D})}$, Pawel Macek ${ }^{1,3} \mathbb{D}$, Izabela Ciepiela ${ }^{2}$, Artur Kowalik ${ }^{4,5}$ and Stanislaw Gozdz ${ }^{1,6}$ \\ 1 Department of Oncology, Institute of Health Sciences, Collegium Medicum, Jan Kochanowski University, \\ 25-713 Kielce, Poland; pawel.macek@onkol.kielce.pl (P.M.); stanislawgozdz1@gmail.com (S.G.) \\ 2 Radiotherapy Clinic, Holycross Cancer Centre, 25-734 Kielce, Poland; izabela.ciepiela@wp.pl \\ 3 Department of Epidemiology and Cancer Control, Holycross Cancer Centre, 25-734 Kielce, Poland \\ 4 Division of Medical Biology, Institute of Biology, Jan Kochanowski University, 25-406 Kielce, Poland; \\ arturko@onkol.kielce.pl \\ 5 Department of Molecular Diagnostics, Holycross Cancer Centre, 25-734 Kielce, Poland \\ 6 Clinical Oncology Clinic, Holycross Cancer Centre, 25-734 Kielce, Poland \\ * Correspondence: piotr.kedzierawski@ujk.edu.pl
}

Citation: Kedzierawski, P.; Macek, P.; Ciepiela, I.; Kowalik, A.; Gozdz, S. Evaluation of Complete Pathological Regression after Neoadjuvant Chemotherapy in Triple-Negative Breast Cancer Patients with BRCA1 Founder Mutation Aided Bayesian A/B Testing Approach. Diagnostics 2021, 11, 1144. https://doi.org/ 10.3390/diagnostics11071144

Academic Editor:

Gustavo Baldassarre

Received: 20 April 2021

Accepted: 21 June 2021

Published: 23 June 2021

Publisher's Note: MDPI stays neutral with regard to jurisdictional claims in published maps and institutional affiliations.

Copyright: (c) 2021 by the authors. Licensee MDPI, Basel, Switzerland. This article is an open access article distributed under the terms and conditions of the Creative Commons Attribution (CC BY) license (https:/ / creativecommons.org/licenses/by/ $4.0 /)$.
Abstract: The aim of this study was to evaluate the probability of pathologic complete regression (pCR) by the BRCA1 gene mutation status in patients with triple-negative breast cancer (TNBC) treated with neoadjuvant chemotherapy. The study involved 143 women (mean age $55.4 \pm 13.1$ years) with TNBC. The BRCA1 mutation was observed in $17 \%$ of the subjects. The most commonly used $(85.3 \%)$ chemotherapy regimen was four cycles of adriamycine and cyclophosphamide followed by 12 cycles of paclitaxel $(4 \mathrm{AC}+12 \mathrm{~T})$. The differences between clinico-pathological factors by BRCA1 status were estimated. Odds ratios and 95\% confidence intervals for pCR vs. non-pCR were calculated using logistic regression. The probability distribution of $\mathrm{PCR}$ based on BRCA1 status was estimated using beta distributions. The presence of T3-T4 tumours, cancer in stages II and III, lymphovascular invasion, and the use of chemotherapy schedules other than $4 \mathrm{AC}+12 \mathrm{~T}$ significantly decreased the odds of pCR. It was established that there was a $20 \%$ chance that pCR in patients with the BRCA1 mutation was $50 \%$ or more times as frequent than in patients without the mutation. Thus, the BRCA1 mutation can be a predictive factor for $\mathrm{PCR}$ in patients with TNBC.

Keywords: breast cancer; triple-negative breast cancer; BRCA1; pathologic complete regression; Bayesian statistics

\section{Introduction}

Breast cancer is the most frequently diagnosed cancer and the second most common cause of cancer mortality in women worldwide [1]. Triple-negative breast cancer (TNBC) accounts for approximately $15-20 \%$ of all breast carcinomas and is immunohistochemically characterized by the lack of oestrogen receptor (ER), progesterone receptor (PR), and human epidermal growth factor receptor (HER2) (also defined by the lack of HER2 amplification by fluorescence in situ hybridization (FISH)). TNBC has a highly aggressive clinical course, with an earlier age of onset, greater metastatic potential, and poorer clinical outcomes [2]. Chemotherapy has become the main approach for the treatment of TNBC. Despite the poor prognosis of TNBC, studies have demonstrated that TNBC is more responsive to chemotherapy than any other molecular subtype [3-5].

At this time, an anthracycline- and taxane-based regimen remains the standard of care for TNBC patients. Neoadjuvant chemotherapy allows for the reduction of tumour volume of the primary tumour and the regional nodes, which can facilitate more options 
for surgical treatment. Preoperative systemic treatment is mostly applied, even in patients with an early stage. However, according to the NSABP B-27 trial, where preoperative or postoperative adriamycine (A) and cyclophosphamide (C) with docetaxel was compared, there was no significant difference in disease-free survival (DFS) and overall survival (OS) [6,7].

Pathologic complete regression ( $\mathrm{pCR}$ ) is defined as the absence of residual invasive cancer or preinvasive cancer on pathologic evaluation of the resected breast and regional lymph nodes after neoadjuvant therapy. Several trials showed that $\mathrm{pCR}$ predicts for longterm outcomes and is, therefore, a potential surrogate marker for DFS and OS. Achieving a pCR is more common in highly proliferating carcinomas like TNBC or HER2-positive tumours as compared to luminal tumours [8]. An analysis comprised of 12 randomized clinical trials of neoadjuvant chemotherapy in breast cancer, conducted by the Collaborative Trials in Neoadjuvant Breast Cancer international working group, showed longer event-free survival (EFS) and OS in patients who achieved a pCR [9].

Studies of neoadjuvant chemotherapy have consistently reported higher response rates in patients with TNBC than those with non-TNBC, and approximately $30-40 \%$ of patients with early-stage TNBC treated with the standard neoadjuvant anthracyclineand taxane-based chemotherapy regimen achieved a pCR after treatment $[4,8,10]$. A preferred chemotherapy regimen in the neoadjuvant or adjuvant setting has not yet been determined, but dose-dense and high-dose regimens seem to be more effective in patients with TNBC [11-13]. Taxanes and anthracyclines are the most effective schedules [14-16]. TNBC commonly harbours BRCA gene mutations that make them particularly susceptible to DNA-damaging compounds such as platinum drugs [17]. The results of recent trials investigating the role of platinum agents in TNBC are conflicting and do not reveal a statistically significant difference due to small populations and, likely, to toxicity and the higher rate of treatment discontinuation in platinum arm [18,19]. BRCA-related breast cancer is characterised by a more aggressive phenotype than sporadic breast cancer, and is more frequently high grade and triple-negative $[17,18]$. For oncologists, it is very important to know BRCA status because it is strongly connected with planning systemic and surgical treatment [20-22]. The aim of this paper is to evaluate the probability of pCR in triplenegative breast cancers patients, treated mostly with the recommended, neoadjuvant schedule AC followed by taxane chemotherapy, based on BRCA1 gene mutation status.

\section{Materials and Methods}

\subsection{Verification of Data}

Data $(n=2745)$ of women treated for breast cancer in 2015-2019 was verified. In the first step of the verification, all patients with breast cancer biological subtypes other than triple-negative breast cancer were removed from the database. Then, the data of women initially treated surgically was removed from the database as well. From the group of patients who received preoperative chemotherapy, 12 cases with an unknown mutation status of the BRCA gene were removed. Ultimately, 143 patients were qualified for the study. Detailed information on data verification is presented in Figure 1.

\subsection{Pathologic Complete Regression Status Determination}

The pathological response was assessed by pathologists after the completion of the neoadjuvant chemotherapy and surgery. Pathologic complete regression was defined as no evidence of residual invasive or preinvasive cancer in the breast, whether the removed whole breast after mastectomy or part of the breast after breast conserving surgery, and in the removed axillary lymph nodes (ypTON0). 


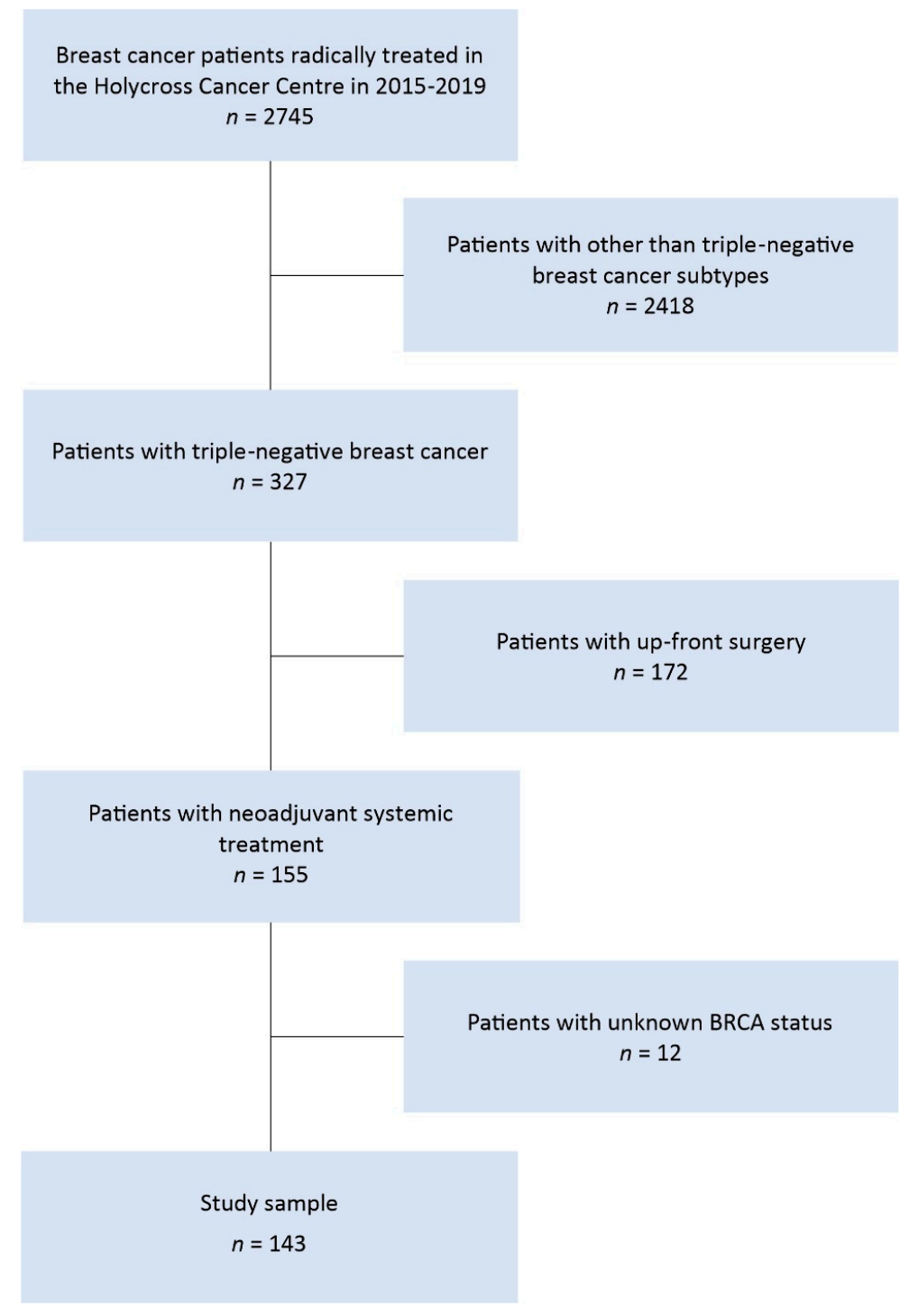

Figure 1. Flow diagram of data selection process.

\subsection{BRCA Status Determination}

\subsubsection{DNA Isolation}

Whole blood collected in EDTA tubes was used for DNA isolation. DNA was isolated from $100 \mu \mathrm{L}$ of whole blood within $12 \mathrm{~h}$ of collection using the Micro AX Blood Gravity Kit (A\&A Biotechnology, Gdańsk, Poland). The DNA was eluted in a volume of $120 \mu \mathrm{L}$ of buffer E.

\subsubsection{High-Resolution Melting (HRM)-Polymerase Chain Reaction (PCR) and Sanger Sequencing}

We have used HRM for 10 years. Before HRM was introduced to detect the founder mutations in BRCA1, this method was validated based on control samples. In addition, several hundred samples were genotyped using both HRM and Sanger technologies. We obtained $100 \%$ concordance in mutation detection using both technologies. To confirm the presence of a mutation detected by HRM with Sanger, we selected more samples for confirmatory Sanger sequencing than could be estimated by analysing HRM curves, which protects against false negative results. Based on the above facts, screened founder and recurrent mutations in BRCA1 (5382insC- c.5266dupC (p.Gln1756Profs), c.5370C > T- c.5251C > T (p.R1751*), 300T>G- c.181T>G (p.Cys61Gly), 185delAG- c.68_69delAG (p.Glu23Valfs), and 4153delA- c.4035delA (p.Glu1346Lysfs)) were all detected with very high confidence. 
PCR was performed using a mixture of $7 \mu \mathrm{L}$ Qiagen Type-it PCR Polymerase Mix (Qiagen, Hilden, Germany), $5 \mu \mathrm{L}$ water, $1 \mu \mathrm{L}$ of each primer (Table 1 ), and $1 \mu \mathrm{L}$ template DNA. The reaction was carried out in a Rotor Gene $Q$ thermocycler (Qiagen). The reaction conditions were: $95^{\circ} \mathrm{C}$ for $5 \mathrm{~min}$; 40 cycles of $95^{\circ} \mathrm{C}$ for $10 \mathrm{~s}, 67^{\circ} \mathrm{C}$ for $30 \mathrm{~s}$ (touchdown of $1{ }^{\circ} \mathrm{C} /$ cycle for $10 \mathrm{cycles}$ ), and $72{ }^{\circ} \mathrm{C}$ for $20 \mathrm{~s}$; and one cycle of $95^{\circ} \mathrm{C}$ for $10 \mathrm{~s}$ and $40^{\circ} \mathrm{C}$ for $20 \mathrm{~s}$. After completion of the PCR reaction, the HRM melting reaction was performed on a Rotor Gene $Q$ thermocycler (Qiagen, Hilden, Germany). The HRM range for the examined exons in the BRCA1 gene was $75-87^{\circ} \mathrm{C}$. The reaction results were analysed, relative to control samples, using the Rotor-Gene Q Series Software Version 2.2.3 (Qiagen, Hilden, Germany). The melting curve profiles of the tested samples were compared with the melting curves of the non-mutated and mutated control samples. All mutations detected using the HRMPCR technique were confirmed using capillary sequencing. Curves diverging in shape from the control curve (WT) were verified by capillary sequencing. The Sanger sequencing reaction used PCR amplification products that were purified using $10 \mathrm{U}$ of exonuclease I (EN 0582) and $1 \mathrm{U}$ of phosphatase Fast-AP (EF 0651) (both from Thermo Fisher Scientific, Waltham, MA, USA). The reaction was incubated for $15 \mathrm{~min}$ at $37^{\circ} \mathrm{C}$, followed by $20 \mathrm{~min}$ at $80{ }^{\circ} \mathrm{C}$. The sequencing reactions were performed using forward $(\mathrm{F})$ and reverse $(\mathrm{R})$ sequence-specific primers (Table 1) and the ABI PRISM Big Dye Terminator Kit, version 3.1 (catalogue number 4337450, Applied Biosystems; Thermo Fisher Scientific, Waltham, MA, USA), according to the manufacturer's instructions. The sequencing results were analysed using the 3130 capillary sequencer (Applied Biosystems; Thermo Fisher Scientific). The generated sequences were compared to the reference sequence using the NCBI Blast Nucleotide program (https:/ / blast.ncbi.nlm.nih.gov/Blast.cgi?PAGE_TYPE=BlastSearch (accessed on 7 April 2021)).

Table 1. The primer sequences used for BRCA1 founder mutations analysis by HRM-PCR and Sanger sequencing.

\begin{tabular}{ccc}
\hline Exon & Sequence-Specific Primers & Primer Sequences \\
\hline \multirow{2}{*}{$B R C A 1$ e 20} & $\mathrm{~F}$ & ATATGACGTGTCTGCTCCAC \\
BRCA1 e 5 & $\mathrm{R}$ & GGGAATCCAAATTACACAGC \\
& $\mathrm{F}$ & CTCTTAAGGGCAGTTGTGAG \\
BRCA1 e2 & $\mathrm{R}$ & TTCCTACTGTGGTTGCTTCC \\
& $\mathrm{F}$ & GAAGTTGTCATTTTATAAACCTTT \\
BRCA1 e11 & $\mathrm{R}$ & TGTCTTTTCCCTAGTATGT \\
& $\mathrm{F}$ & CAGGGAGTTGGTCTGAGTGAC \\
\hline
\end{tabular}

Abbreviations: F-forward, R-reverse, A-adenine, T-thymine, G-guanine, and C-cytosine.

\subsection{Statistical Analyses}

Basic statistics were presented as mean \pm standard deviation or number and proportion, depending on the type of the studied variable. Statistical differences, depending on the mutation status of the BRCA1 gene, were estimated using a $t$-test (equal variance), Welch test (unequal variance), or the chi-square test (categorical variables). Equality of variance was checked with the $\mathrm{F}$ test. The odds ratios (ORs) and $95 \%$ confidence intervals ( $95 \% \mathrm{CI}$ ) for $\mathrm{pCR}$ vs. non-pCR, in relation to clinico-pathological factors, were calculated using logistic regression models. The confidence intervals were based on the log-likelihood ratio. $p$ values of $<0.05$ were considered statistically significant. In Table 2 , statistical significance is marked with asterisks $\left({ }^{*} p<0.05 ;{ }^{* *} p<0.01\right.$; and $\left.{ }^{* * *} p<0.001\right)$. The probability distribution of $\mathrm{pCR}$ based on the available data, depending on the mutation status of the BRCA1 gene, was estimated on the basis of the beta distributions. Functions describing the probability of each possible pCR hypothesis were obtained provided that $\alpha \mathrm{pCR}$ events and $\beta$ non-pCR events occurred for each analysed BRCA1 mutation status. Based on the available literature, in patients with triple-negative breast cancer, a BRCA1 mutation, and neoadjuvant chemotherapy, the $\mathrm{pCR}$ rate was $\approx 40 \%$ and $\approx 30 \%$ in patients without the BRCA1 gene mutation $[23,24]$. Therefore, two different prior beta distributions were 
adopted for the pCR probability according to the mutation status of the BRCA1 gene: beta distribution $(3,7)$ for patients without the mutation, and beta distribution $(4,6)$ for patients with the mutation. The mean probabilities of $\mathrm{pCR}$ for the non-mutated and mutated patients were 0.3 and 0.4 , respectively. The means of the analysed beta distributions were calculated on the basis of the following formula:

$$
\text { mean beta distribution }=\alpha /(\alpha+\beta)
$$

Table 2. Basic characteristic of study group by BRCA1 status.

\begin{tabular}{|c|c|c|c|}
\hline Characteristic & $\begin{array}{l}\text { No BRCA1 Mutation } \\
\quad(n=119)\end{array}$ & $\begin{array}{l}\text { BRCA1 Mutation } \\
\quad(n=24)\end{array}$ & $p$ \\
\hline $\begin{array}{l}\text { Age (years), mean } \pm S D \\
\text { Cancer side }\end{array}$ & $57.1 \pm 12.5$ & $47.0 \pm 12.9$ & $<0.001$ \\
\hline Cancer side & & & $>0.05$ \\
\hline Right & $62(52.1)$ & $11(45.8)$ & \\
\hline Left & $57(47.9)$ & $13(54.2)$ & \\
\hline Cancer type & & & $>0.05$ \\
\hline NST & $105(88.2)$ & $23(95.8)$ & \\
\hline Other \# & $14(11.8)$ & $1(4.2)$ & \\
\hline Ki-67, mean \pm SD & $64.3 \pm 25.8$ & $77.3 \pm 17.6$ & $<0.001$ \\
\hline Tumour size & & & $>0.05$ \\
\hline T1 & $5(4.2)$ & $3(12.5)$ & \\
\hline $\mathrm{T} 2$ & $62(52.1)$ & $16(66.7)$ & \\
\hline T3 & $35(29.4)$ & $5(20.8)$ & \\
\hline $\mathrm{T} 4$ & 17 (14.3) & no & \\
\hline Nodal status & & & $>0.05$ \\
\hline Nodes negative $(\mathrm{cN}-$ ) & $72(60.5)$ & $18(75.0)$ & \\
\hline Nodes positive $(\mathrm{cN}+)$ & $47(39.5)$ & $6(25.0)$ & \\
\hline Clinical stage (CS) & & & $<0.01$ \\
\hline I & $44(37.0)$ & $17(70.8)$ & \\
\hline II & $56(47.1)$ & $7(29.2)$ & \\
\hline III & $19(16.0)$ & no & \\
\hline Grading (G) & & & $>0.05$ \\
\hline G1 & $4(3.4)$ & no & \\
\hline G2 & $56(47.1)$ & $7(29.2)$ & \\
\hline G3 & 59 (49.6) & $17(70.8)$ & \\
\hline LVI & & & $<0.05$ \\
\hline Yes & $30(25.2)$ & $1(4.2)$ & \\
\hline No & $89(74.8)$ & $23(95.8)$ & \\
\hline PNI & & & $>0.05$ \\
\hline Yes & $4(3.4)$ & no & \\
\hline No & $115(96.6)$ & $24(100)$ & \\
\hline CHTH & & & $>0.05$ \\
\hline $4 \mathrm{AC}+12 \mathrm{~T}$ & $101(84.9)$ & $21(87.5)$ & \\
\hline $\mathrm{AC} / \mathrm{EC}+\mathrm{T}+$ Carboplatin & $9(7.6)$ & $2(8.3)$ & \\
\hline Other $^{\dagger}+$ & $9(7.6)$ & $1(4.2)$ & \\
\hline Type of surgery & & & $<0.001$ \\
\hline BCT & $40(33.6)$ & $1(4.2)$ & \\
\hline Radical mastectomy & $51(42.9)$ & $1(4.2)$ & \\
\hline Simple mastectomy & $7(5.9)$ & $3(12.5)$ & \\
\hline $\begin{array}{l}\text { Skin sparing or nipple-sparing } \\
\text { mastectomy }\end{array}$ & $21(17.7)$ & $19(79.2)$ & \\
\hline pCR (ypT0 ypN0) & & & $>0.05$ \\
\hline Yes & $48(40.3)$ & $13(54.2)$ & \\
\hline No & $71(59.7)$ & $11(45.8)$ & \\
\hline Time 1 (days), mean $\pm \mathrm{SD}$ & $167.3 \pm 73.0$ & $161.5 \pm 19.0$ & $>0.05$ \\
\hline Time 2 (days), mean \pm SD & $34.8 \pm 18.0$ & $33.0 \pm 22.3$ & $>0.05$ \\
\hline
\end{tabular}

Notes: Data is presented as number (percentage) unless stated otherwise. \# category contains specific types of cancer: apocrinal, metaplastic, lobular, and medullar; ${ }^{\dagger}$ category contains: E-epirubicin, C-cyclophosphamide, F- fluorouracil, EC, FA-adriamycine, C, AC, AT- taxotere; Time 1: the time from the start to the end of chemotherapy; Time 2: the time from the end of chemotherapy to the surgery. Abbreviations: NST-no special type; LVI-lymphovascular invasion; PNI-perineural invasion; CHTH-chemotherapy; BCT-breast conserving treatment; and pCR-pathological complete regression. 
At the same time, in both cases, a wide range of alternative pCR probabilities was allowed. In order to obtain a posterior distribution, the reliability based on the available data was combined (the sum of the parameters of beta distributions) with the assumed prior distributions of pCR depending on the BRCA1 mutation status. The posterior beta distribution was calculated based on the following formula:

$$
\operatorname{Beta}\left(\alpha_{\text {posterior }}, \beta_{\text {posterior }}\right)=\operatorname{Beta}\left(\alpha_{\text {likelihood }}+\alpha_{\text {prior }}, \beta_{\text {likelihood }}+\beta_{\text {prior }}\right)
$$

The $95 \%$ credible intervals were established on the basis of the quantile function for the beta distribution, determining quantiles of the order of 0.025 and 0.975 separately for each analysed BRCA1 gene mutation status. The assessment of which mutation status of the BRCA1 gene generated a higher probability of pCR was performed using Monte Carlo simulation, a technique that, in this study, used random sampling from two beta distributions, where each sample was selected based on its probability in the distribution. As a result, samples from high-probability areas were selected more frequently. Sampling from two beta distributions was treated as one sample. Considering the influence of the number of trials on the accuracy of the result, 100,000 trials were taken. Then, it was compared from which distribution the samples were taken more frequently, and the result obtained was divided by the total number of samples. In this way, the percentage of all trials, where one of the two BRCA1 mutation statuses generated a higher probability of pCR than the other, was calculated. Using the simulation results, the number of times samples from the beta distribution of the BRCA1 gene mutation status, which generated a higher probability of pCR, were taken more often was estimated (Formula (3)):

probability superior $=\operatorname{sum}($ superior samples $>$ inferior samples $) /$ number of trials

Based on the quotient of the analysed distributions, where the numerator was the beta distribution of the BRCA1 mutation status with a higher probability of pCR, the distribution of relative improvements between the analysed distributions was determined (Formula (4)):

distribution of the relative improvements $=$ superior samples/inferior samples

The results of this analysis were illustrated by the empirical cumulative distribution, on the basis of which the 25th, 50th, and 75th percentiles were determined. All statistical analyses were performed in $\mathrm{R}$ (version 3.5.3).

\section{Results}

The study involved 143 women (mean age $55.4 \pm 13.1$ years) treated with neoadjuvant systemic treatment for triple-negative breast cancer between 2015 and 2019.The method to determine ER, PgR, and HER2 negativity was used according to the American Society of Clinical Oncology, College of American Pathologists guidelines: ER and PgR nuclear staining of less than $1 \%$ by immunohistochemistry (IHC) and HER2 IHC staining of 0 to 1+ or fluorescent in situ hybridization $<2.0$ if IHC 2+ or IHC not performed. The dominant type was NST carcinoma, observed in $89.5 \%$ of the patients, while T2 tumour stage was diagnosed in more than half of the patients, and no lymph node metastases were present in $62.9 \%$. More than half of the tumours were grade III. Lymphovascular invasion (LVI) and perineural invasion (PNI) were observed in $21.7 \%$ and $2.8 \%$ of the patients, respectively. Pathological complete regression (pCR) was reported in $42.7 \%$ of the women. The most commonly used $(85.3 \%)$ chemotherapy regimen was four cycles of adriamycine and cyclophosphamide, followed by 12 cycles of paclitaxel $(4 \mathrm{AC}+12 \mathrm{~T})$, in 122 women. In 21 patients, other schedules of chemotherapy were applied: epirubicin (E) or adriamycine (A) with cyclophosphamide and taxol (T) with carboplatin (C), or adriamycine or epirubicin with taxol or cyclophosphamide. Breast-conserving surgery was performed in $28.7 \%$ of the women. The BRCA1 mutation was observed in $17 \%(n=24)$ of the subjects. Significant differences between patients with either 
BRCA1 mutation status were noted in age, histological grade, lymphovascular invasion, and surgical treatment methods (Table 2).

The odds of pCR occurrence were strongly associated with the tumour size, nodal status, staging, lymphovascular invasion, and the chemotherapy schedule used. The presence of T3-T4 tumours, cancers in stage II and III, lymphovascular invasion, and the use of chemotherapy schedules other than $4 \mathrm{AC}+12 \mathrm{~T}$ significantly reduced the chance of pCR (Table 3).

Table 3. ORs (95\% CIs) of pCRs vs. non-pCRs associated with clinico-pathological factors.

\begin{tabular}{|c|c|}
\hline Characteristic & OR $(95 \%$ CI $)$ \\
\hline \multicolumn{2}{|l|}{ BRCA1 mutation status } \\
\hline BRCA1 positive vs. BRCA1 negative & $1.75(0.72,4.3)$ \\
\hline Age (years) & $0.97(0.95,1.00)$ \\
\hline \multicolumn{2}{|l|}{ Cancer type } \\
\hline NST vs. other \# & $1.56(0.52,5.23)$ \\
\hline Ki-67 & $1.01(1.00,1.03)$ \\
\hline \multicolumn{2}{|l|}{ Tumour size } \\
\hline T2 vs. T1 & $0.17(0.01,0.99)$ \\
\hline $\mathrm{T} 3$ vs. $\mathrm{T} 1$ & $0.05(0.01,0.31) * *$ \\
\hline T4 vs. T1 & $0.02(0.01,0.18) * *$ \\
\hline \multicolumn{2}{|l|}{ Nodal status } \\
\hline Node positive vs. node negative & $0.43(0.21,0.88) *$ \\
\hline \multicolumn{2}{|l|}{ Staging } \\
\hline Stage II vs. stage I & $0.32(0.15,0.67) * *$ \\
\hline Stage III vs. stage I & $0.12(0.03,0.41) * *$ \\
\hline \multicolumn{2}{|l|}{ Grading } \\
\hline G2 vs. G1 & $0.85(0.10,7.47)$ \\
\hline G3 vs. G1 & $0.65(0.07,5.67)$ \\
\hline \multicolumn{2}{|l|}{ LVI } \\
\hline Yes vs. No & $0.03(0.01,0.14)^{* * *}$ \\
\hline $\mathrm{CHTH}$ & \\
\hline $4 \mathrm{AC}+12 \mathrm{~T}$ vs. other ${ }^{+}$ & $5.44(1.73,24.07) * *$ \\
\hline Time 1 (days) & $1.00(0.99,1.00)$ \\
\hline Time 2 (days) & $0.99(0.97,1.01)$ \\
\hline
\end{tabular}

Notes: ${ }^{\#}$ category contains specific types of cancer: apocrinal, metaplastic, lobular, and medullar; ${ }^{\dagger}$ category contains different schedules of CHTH: EC, FEC, FAC, AC, AT, and schedules with carboplatin; Time 1: the time from the start to the end of chemotherapy; Time 2: the time from the end of chemotherapy to the surgery; ${ }^{*} p<0.05 ;{ }^{* *} p<0.01$; and ${ }^{* * *} p<0.001$. Abbreviations: NST-no special type; LVI- lymphovascular invasion; CHTH-chemotherapy; and BCT-breast conserving treatment.

The remaining tested features showed no association with the $\mathrm{pCR}$ and they were not significant. The described situation was noted in the case of the BRCA1 gene mutation, the presence of which, although insignificantly, increased the odds of $\mathrm{pCR}$ by $75 \%$. Since in the study group, the BRCA1 mutation was observed only in $18 \%(n=24)$ of patients, and the presence of $\mathrm{pCR}$ in 13 patients, it was assumed that a small number of $\mathrm{pCR}$ and non-pCR events influenced the results of the presented estimates. For this reason, it was decided to change the data mining method to using the Bayesian approach.

Probability distributions of $\mathrm{pCR}$ based on the available data depending on the mutation status of the BRCA1 gene were estimated based on the beta distributions (Figure 2). The $95 \%$ credible intervals of the $\mathrm{pCR}$ of beta distributions for patients without the BRCA1 mutation and with the current mutation were $31.7-49.3 \%$ and $34.5-73.2 \%$, respectively. In the case of both estimated ranges, their upper limits indicated a high, and in the case of BRCA1 positive, a very high probability of $\mathrm{pCR}$. The probability of $73 \%$ of $\mathrm{pCR}$ in patients with BRCA1 mutation seemed particularly unlikely. To obtain beta posterior 
distributions, the credibility based on the available data was combined with the assumed prior distributions of $\mathrm{pCR}$ probability depending on BRCA1 mutation status (Formula (2)).

$$
\begin{aligned}
& \text { Beta }_{\text {posterior } B R C A 1 \text { negative }}=\operatorname{Beta}(48+3.71+7) \\
& \text { Beta }_{\text {posterior } B R C A 1 \text { positive }}=\operatorname{Beta}(13+4.11+6)
\end{aligned}
$$

A

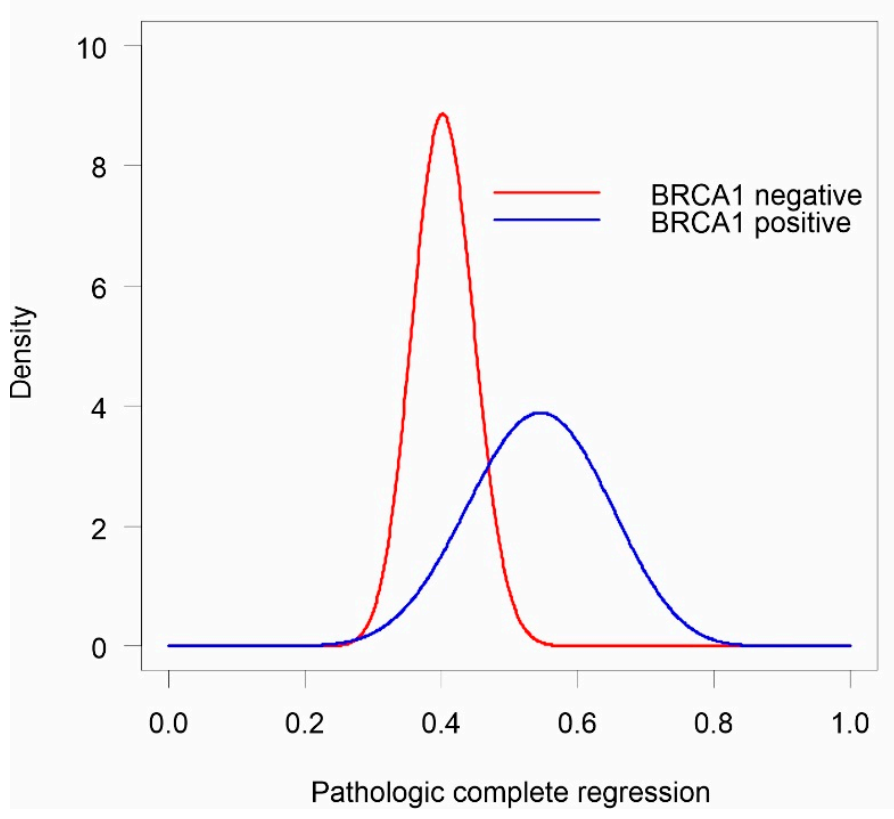

B

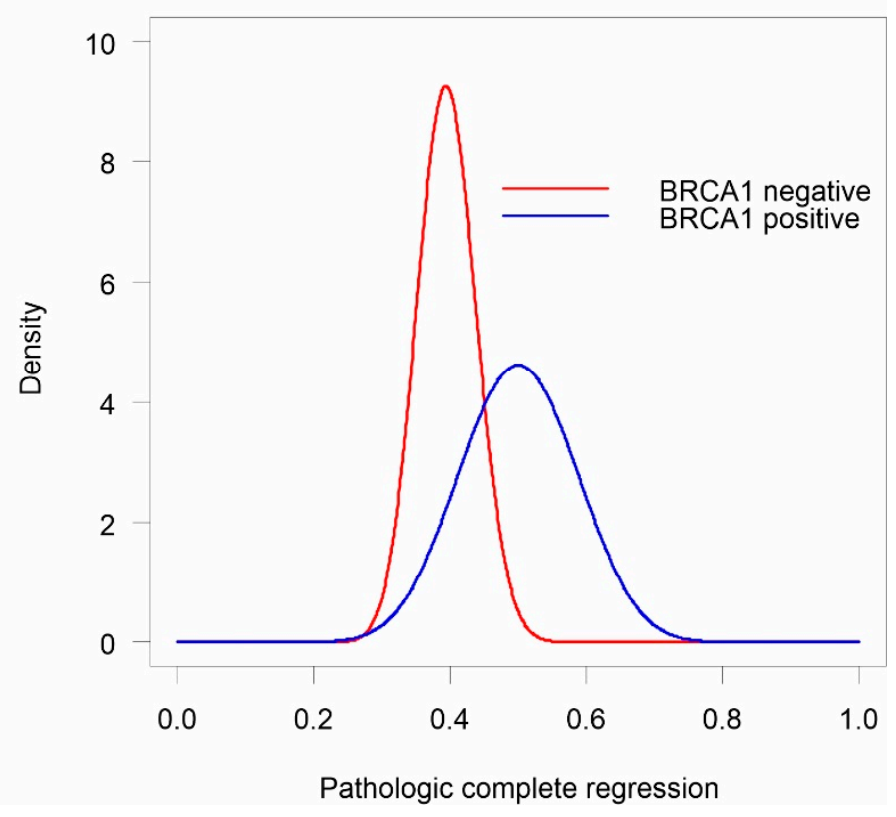

Figure 2. Beta distributions of pCR depending on the mutation status of the BRCA1 gene. The (A) available data, and (B) posterior distributions.

The posterior results indicated that in patients with the mutation, a higher probability of pCR was observed, but also a wider range of its possible probability. Based on beta posterior distributions, the $95 \%$ credible intervals of the $\mathrm{PCR}$ for patients without the BRCA1 mutation and with the mutation were $31.3-48.1 \%$ and $33.5-66.5 \%$, respectively. Unfortunately, the $\mathrm{pCR}$ probability distributions of both analysed beta distributions overlapped. Therefore, it could not be unequivocally ruled out that PCR in patients without the mutation is much more likely than in patients with the mutation (Figure 2).

To dispel any doubts, the Monte Carlo simulation was used, automatically drawing 100,000 samples simultaneously from both analysed beta distributions. Following this, we estimated the percentage of all trials in which the beta distribution of possible pCR of mutated patients was more likely than in patients without the mutation. Based on all the tests performed, the distribution of possible pCRs for patients with the mutation was $86 \%$ better when compared to patients without the mutation (Formula (3)):

sum(BRCA1 positive beta samples $>$ BRCA1 negative beta samples) $/ 100,000=0.86$

In the frequency statistics, this result was equivalent to obtaining the value of $p=0.14$. As this result was not statistically significant, it can be concluded that the $\mathrm{PCR}$ probability distributions in patients with and without the BRCA1 mutation did not differ significantly from each other. However, the lack of statistically significant differences meant no differences at all and did not specify how much the PCR probabilities by BRCA1 gene mutation status were different from each other. Using the results of the Monte Carlo simulation, the 
quotient of the $\mathrm{PCR}$ probability distributions was calculated depending on the mutation status of the BRCA1 gene (Formula (4)):

$$
\begin{aligned}
& \text { distribution of the relative improvements } \\
& =\text { BRCA1 positive beta samples/BRCA1 negative beta samples }
\end{aligned}
$$

The results are presented graphically in the form of empirical cumulative distribution (Figure 3).

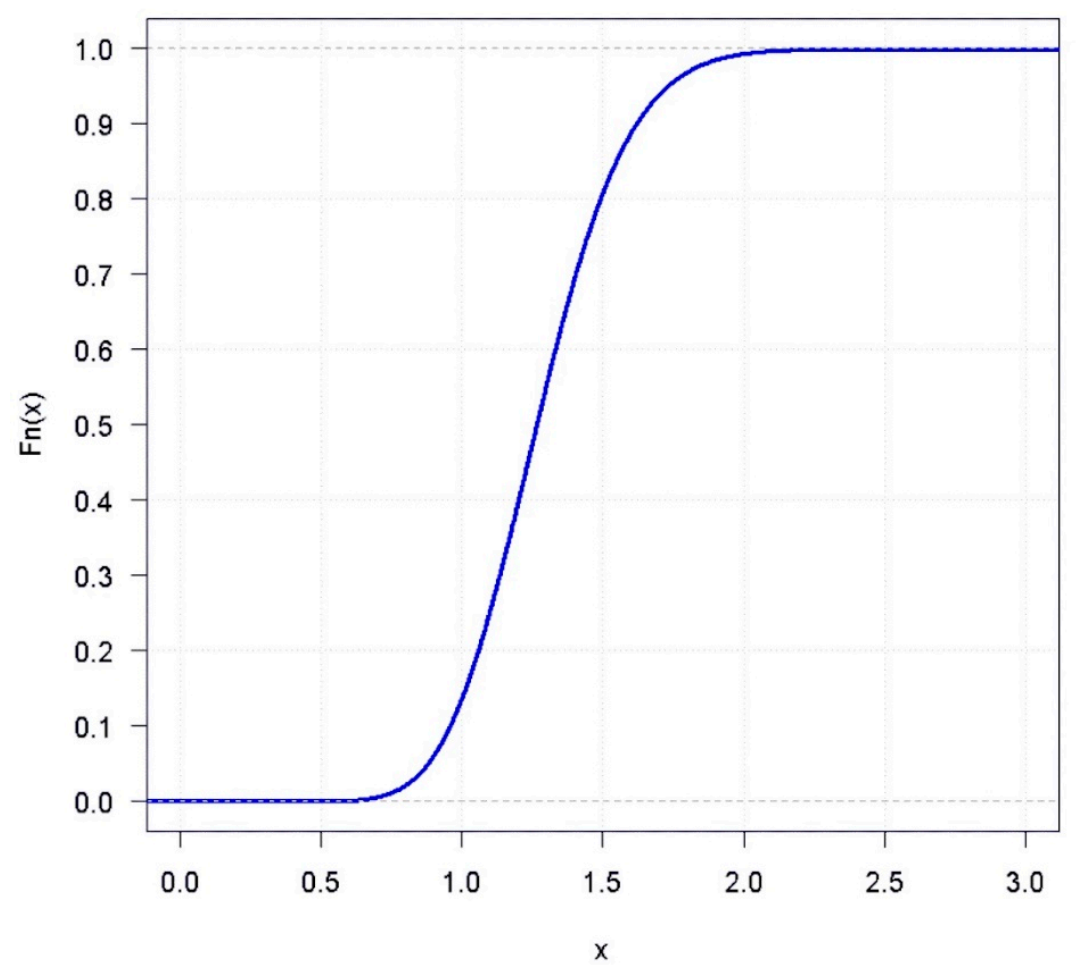

Figure 3. Empirical cumulative distribution.

The 25th, 50th, and 75th percentile values were 1.10, 1.26, and 1.44, respectively, indicating a higher probability of $\mathrm{pCR}$ in patients with the mutation. It was also estimated that there was a $20 \%$ chance that pCR in patients with the BRCA1 mutation was $50 \%$ or more times as frequent than in patients without the mutation.

\section{Discussion}

Pathologic complete regression is the crucial factor for patients receiving neoadjuvant chemotherapy. A recently published cohort study with prospective follow-up of patients treated with an anthracycline- and taxane-based neoadjuvant chemotherapy regimen demonstrated an estimated 10-year relapse-free survival of $86 \%$ for TNBC patients who achieved pCR, versus only $23 \%$ for those with significant residual disease after chemotherapy [24]. In our group, most patients were treated with taxane-based schedules with adriamycine and cyclophosphamide. In the BRCA-mutated group, statistically, most patients achieved pCR after AC followed by paclitaxel in comparison to no BRCA-mutated patients. As is shown in Table 1, time from the beginning of chemotherapy to its end was not prolonged and we did not notice high toxicity, which was connected with interruptions or prolongations of the systemic treatment.

As already discussed, triple-negative breast cancer is strongly associated with germline mutations in the BRCA1 gene and can be much more sensitive to platinum agents [25]. In our study group, platinum agents were added to schedules of standard chemotherapy, but the number of patients was limited. And in most patients, the systemic treatment with plat- 
inum agents was interrupted or terminated due to acute toxicity. Several non-randomized clinical trials showed that a single-agent platinum-based therapy was an active regimen in BRCA-mutated breast cancer patients, especially in those with TNBC [25-28]. However, available data on the benefit of adding a platinum agent in BRCA-mutated patients receiving standard neoadjuvant chemotherapy are more limited and controversial. So far, only two randomized trials reported PCR results according to germline BRCA mutational status [23,27]. Pooled results from these trials showed that the addition of carboplatin to paclitaxel followed by anthracycline plus cyclophosphamide was not associated with a significant increased pCR rate in BRCA-mutated breast cancer patients (OR 1.17, 95\% CI 0.51-2.67, and $p=0.711$, while the benefit was present in patients without BRCA mutations (OR 2.72, 95\% CI 1.71-4.32, and $p<0.001$ ). Several neoadjuvant clinical trials evaluated the impact of adding platinum to standard chemotherapy. Silver et al. showed a pCR rate of $22 \%$ among all TNBC patients given neoadjuvant cisplatin [29]. The GeparSixto trial demonstrated a significant improvement in $\mathrm{pCR}$ with carboplatin $(p=0.005)$ in patients with TNBC. However, the toxicities in the carboplatin arm caused a significantly higher rate of treatment discontinuation compared to the no carboplatin arm [30]. In the CALGB 40603 trial, a standard chemotherapy of weekly paclitaxel for 12 weeks followed by dosedense doxorubicin and cyclophosphamide for four cycles was evaluated. The analysis revealed that the pCR rate was significantly increased with carboplatin (54\%) compared with the control arm (41\%). The survival data at 3 years did not demonstrate a significant improvement with carboplatin; however, the study was not powered to detect event-free survival [18]. The effect of cyclophosphamide was also supported by the GeparOcto trial, addressing the question of whether the high-dose intensity combination of epirubicin, taxane, and cyclophosphamide is equivalent to the carboplatin-containing treatment schedule of paclitaxel, liposomal doxorubicin, and carboplatin. This study suggested carboplatin and high-dose cyclophosphamide may be interchangeable, in combination with taxane and anthracycline, with similar pCR rates in both arms [31]. At this time, an anthracycline and taxane-based regimen remains the standard of care for TNBC patients [32,33].

This study has limitations that should be mentioned. Firstly, we decided to analyse only the impact of the presence of founder mutations in BRCA1 on PCR because they account for about $70 \%$ of all mutations detected in BRCA1 and BRCA2 genes in the Polish population [34] and mutations in BRCA1 are more frequent in TNBC [35]. Secondly, the relative deficiency of patients with the BRCA1 mutation $(17 \% ; n=24)$ could have influenced the bias of the obtained results. Thirdly, the high percentage of pCR (54\%) in the small group of patients with the current BRCA1 mutation seemed to be rather a feature of the studied group of patients compared to the population of patients with similar clinical and pathological parameters. Fourthly, the assumed prior beta distributions for pCR probability by BRCA1 mutation status were, perhaps, the most controversial aspect of this study as they are subjective. However, in this particular case, there was prior information about the problem under investigation, and the adoption of prior assumptions allowed for better inference based on a small amount of data. It was also assumed that if the adopted prior distributions were too subjective, they would be updated in the future through an iterative process of data collection.

\section{Conclusions}

As our data showed, the BRCA mutation can be the predictive factor for $\mathrm{PCR}$ in patients with TNBC. The chemotherapy regimen with adriamycine, cyclophosphamide, and taxans can be effectively used in triple-negative breast cancer patients, even with BRCA1 mutation.

Author Contributions: Conceptualization: P.K. and P.M.; methodology: P.M. and P.K.; software: P.K., I.C.; formal analysis: P.M. and P.K.; investigation: P.K., I.C., P.M., and A.K.; resources: P.K., A.K., and S.G.; data curation: P.K.; writing-original draft preparation: P.K. and A.K.; writing-review and editing: P.K., P.M., I.C., and A.K.; visualization: P.M.; supervision: S.G.; project administration: P.K. All authors have read and agreed to the published version of the manuscript. 
Funding: The project is supported under the programme established by the Minister of Science and Higher Education—“Regional Initiative of Excellence" —spanning the period 2019-2022; Project No 024/RID/2018/19; amount of financing allocated: PLN 11999 000.00.

Institutional Review Board Statement: The study was conducted according to the guidelines of the Declaration of Helsinki. We have not asked for approval of the Ethics Committee due to the retrospective character of the analysis. Upon the admission to hospital, the written consent of the patients to be used in the study was obtained.

Informed Consent Statement: Informed consent was obtained from all subjects involved in the study.

Data Availability Statement: The data presented in this study are available on request from the corresponding author. The data are not publicly available due to privacy limitations.

Conflicts of Interest: The authors report no conflicts of interest.

\section{References}

1. Torre, L.A.; Bray, F.; Siegel, R.L.; Ferlay, J.; Lortet-Tieulent, J.; Jemal, A. Global Cancer Statistics, 2012: Global Cancer Statistics, 2012. CA Cancer J. Clin. 2015, 65, 87-108. [CrossRef]

2. Yin, L.; Duan, J.J.; Bian, X.W.; Yu, S.C. Triple-negative breast cancer molecular subtyping and treatment progress. Breast Cancer Res. 2020, 22, 61. [CrossRef]

3. Khosravi-Shahi, P.; Cabezón-Gutiérrez, L.; Aparicio Salcedo, M.I. State of art of advanced triple negative breast cancer. Breast J. 2019, 25, 967-970. [CrossRef]

4. Chaudhary, L.N.; Hope Wilkinson, K.; Kong, A. Triple-Negative Breast Cancer: Who Should Receive Neoadjuvant Chemotherapy? Surg. Oncol. Clin. 2018, 27, 141-153. [CrossRef] [PubMed]

5. Carey, L.A.; Dees, E.C.; Sawyer, L.; Gatti, L.; Moore, D.T.; Collichio, F.; Ollila, D.W.; Sartor, C.I.; Graham, M.L.; Perou, C.M. The Triple Negative Paradox: Primary Tumor Chemosensitivity of Breast Cancer Subtypes. Clin. Cancer Res. 2007, 13, $2329-2334$. [CrossRef]

6. $\quad$ Bear, H.D.; Anderson, S.; Smith, R.E.; Geyer, C.E.; Mamounas, E.P.; Fisher, B.; Brown, A.M.; Robidoux, A.; Margolese, R.; Kahlenberg, M.S.; et al. Sequential Preoperative or Postoperative Docetaxel Added to Preoperative Doxorubicin plus Cyclophosphamide for Operable Breast Cancer: National Surgical Adjuvant Breast and Bowel Project Protocol B-27. J. Clin. Oncol. 2006, 24, 2019-2027. [CrossRef]

7. Rastogi, P.; Anderson, S.J.; Bear, H.D.; Geyer, C.E.; Kahlenberg, M.S.; Robidoux, A.; Margolese, R.G.; Hoehn, J.L.; Vogel, V.G.; Dakhil, S.R.; et al. Preoperative Chemotherapy: Updates of National Surgical Adjuvant Breast and Bowel Project Protocols B-18 and B-27. J. Clin. Oncol. 2008, 26, 778-785. [CrossRef] [PubMed]

8. Haque, W.; Verma, V.; Hatch, S.; Klimberg, V.S.; Butler, E.B.; Teh, B.S. Response rates and pathologic complete response by breast cancer molecular subtype following neoadjuvant chemotherapy. Breast Cancer Res. Treat. 2018, 170, 559-567. [CrossRef] [PubMed]

9. Cortazar, P.; Zhang, L.; Untch, M.; Mehta, K.; Costantino, J.P.; Wolmark, N.; Bonnefoi, H.; Cameron, D.; Gianni, L.; Valagussa, P.; et al. Pathological Complete Response and Long-Term Clinical Benefit in Breast Cancer: The CTNeoBC Pooled Analysis. Lancet 2014, 384, 164-172. [CrossRef]

10. Darb-Esfahani, S.; Loibl, S.; Müller, B.M.; Roller, M.; Denkert, C.; Komor, M.; Schlüns, K.; Blohmer, J.U.; Budczies, J.; Gerber, B.; et al. Identification of Biology-Based Breast Cancer Types with Distinct Predictive and Prognostic Features: Role of Steroid Hormone and HER2 Receptor Expression in Patients Treated with Neoadjuvant Anthracycline/Taxane-Based Chemotherapy. Breast Cancer Res. 2009, 11, R69. [CrossRef]

11. Citron, M.L.; Berry, D.A.; Cirrincione, C.; Hudis, C.; Winer, E.P.; Gradishar, W.J.; Davidson, N.E.; Martino, S.; Livingston, R.; Ingle, J.N.; et al. Randomized Trial of Dose-Dense versus Conventionally Scheduled and Sequential versus Concurrent Combination Chemotherapy as Postoperative Adjuvant Treatment of Node-Positive Primary Breast Cancer: First Report of Intergroup Trial C9741/Cancer and Leukemia Group B Trial 9741. J. Clin. Oncol. 2003, 21, 1431-1439. [CrossRef] [PubMed]

12. Early Breast Cancer Trialists' Collaborative Group (EBCTCG). Long-term outcomes for neoadjuvant versus adjuvant chemotherapy in early breast cancer: Meta-analysis of individual patient data from ten randomised trials. Lancet Oncol. 2018, 19, 27-39. [CrossRef]

13. Gluz, O.; Nitz, U.A.; Harbeck, N.; Ting, E.; Kates, R.; Herr, A.; Lindemann, W.; Jackisch, C.; Berdel, W.E.; Kirchner, H.; et al. Triple-Negative High-Risk Breast Cancer Derives Particular Benefit from Dose Intensification of Adjuvant Chemotherapy: Results of WSG AM-01 Trial. Ann. Oncol. 2008, 19, 861-870. [CrossRef]

14. Lebert, J.M.; Lester, R.; Powell, E.; Seal, M.; McCarthy, J. Advances in the systemic treatment of triple-negative breast cancer. Curr. Oncol. 2018, 25 (Suppl. 1), S142-S150. [CrossRef]

15. Mazouni, C.; Kau, S.-W.; Frye, D.; Andre, F.; Kuerer, H.M.; Buchholz, T.A.; Symmans, W.F.; Anderson, K.; Hess, K.R.; Gonzalez-Angulo, A.M.; et al. Inclusion of Taxanes, Particularly Weekly Paclitaxel, in Preoperative Chemotherapy Improves Pathologic Complete Response Rate in Estrogen Receptor-Positive Breast Cancers. Ann. Oncol. 2007, 18, 874-880. [CrossRef] 
16. Hayes, D.F.; Thor, A.D.; Dressler, L.G.; Weaver, D.; Edgerton, S.; Cowan, D.; Broadwater, G.; Goldstein, L.J.; Martino, S.; Ingle, J.N.; et al. HER2 and Response to Paclitaxel in Node-Positive Breast Cancer. N. Engl. J. Med. 2007, 357, 1496-1506. [CrossRef] [PubMed]

17. Lehmann, B.D.; Bauer, J.A.; Schafer, J.M.; Pendleton, C.S.; Tang, L.; Johnson, K.C.; Chen, X.; Balko, J.M.; Gómez, H.; Arteaga, C.L.; et al. PIK3CA Mutations in Androgen Receptor-Positive Triple Negative Breast Cancer Confer Sensitivity to the Combination of PI3K and Androgen Receptor Inhibitors. Breast Cancer Res. 2014, 16, 406. [CrossRef]

18. Sikov, W.M.; Berry, D.A.; Perou, C.M.; Singh, B.; Cirrincione, C.T.; Tolaney, S.M.; Kuzma, C.S.; Pluard, T.J.; Somlo, G.; Port, E.R.; et al. Impact of the Addition of Carboplatin and/or Bevacizumab to Neoadjuvant Once-per-Week Paclitaxel Followed by Dose-Dense Doxorubicin and Cyclophosphamide on Pathologic Complete Response Rates in Stage II to III Triple-Negative Breast Cancer: CALGB 40603 (Alliance). J. Clin. Oncol. 2015, 33, 13-21. [CrossRef]

19. Sikov, W.; Berry, D.A.; Perou, C.M.; Singh, B.; Cirrincione, C.T.; Tolaney, S.M.; Somlo, G.; Port, E.R.; Qamar, R.; Sturtz, K.; et al. Abstract S2-05: Event-Free and Overall Survival Following Neoadjuvant Weekly Paclitaxel and Dose-Dense AC/-Carboplatin and/or Bevacizumab in Triple-Negative Breast Cancer: Outcomes from CALGB 40603 (Alliance). Cancer Res. 2016. [CrossRef]

20. Bianchini, G.; Balko, J.M.; Mayer, I.A.; Sanders, M.E.; Gianni, L. Triple-negative breast cancer: Challenges and opportunities of a heterogeneous disease. Nat. Rev. Clin. Oncol. 2016, 13, 674-690. [CrossRef]

21. Maksimenko, J.; Irmejs, A.; Nakazawa-Miklasevica, M.; Melbarde-Gorkusa, I.; Trofimovics, G.; Gardovskis, J.; Miklasevics, E. Prognostic Role of BRCA1 Mutation in Patients with Triple-Negative Breast Cancer. Oncol. Lett. 2014, 7, 278-284. [CrossRef]

22. Clifton, K.; Gutierrez-Barrera, A.; Ma, J.; Bassett, R.; Litton, J.; Kuerer, H.; Moulder, S.; Albarracin, C.; Hortobagyi, G.; Arun, B. Adjuvant versus Neoadjuvant Chemotherapy in Triple-Negative Breast Cancer Patients with BRCA Mutations. Breast Cancer Res. Treat. 2018, 170, 101-109. [CrossRef]

23. Hahnen, E.; Lederer, B.; Hauke, J.; Loibl, S.; Kröber, S.; Schneeweiss, A.; Denkert, C.; Fasching, P.A.; Blohmer, J.U.; Jackisch, C.; et al. Germline Mutation Status, Pathological Complete Response, and Disease-Free Survival in Triple-Negative Breast Cancer: Secondary Analysis of the GeparSixto Randomized Clinical Trial. JAMA Oncol. 2017, 3, 1378-1385. [CrossRef]

24. Symmans, W.F.; Wei, C.; Gould, R.; Yu, X.; Zhang, Y.; Liu, M.; Walls, A.; Bousamra, A.; Ramineni, M.; Sinn, B.; et al. Long-Term Prognostic Risk After Neoadjuvant Chemotherapy Associated With Residual Cancer Burden and Breast Cancer Subtype. J. Clin. Oncol. 2017, 35, 1049-1060. [CrossRef]

25. Tutt, A.; Tovey, H.; Cheang, M.C.U.; Kernaghan, S.; Kilburn, L.; Gazinska, P.; Owen, J.; Abraham, J.; Barrett, S.; Barrett-Lee, P.; et al. Carboplatin in BRCA1/2-Mutated and Triple-Negative Breast Cancer BRCAness Subgroups: The TNT Trial. Nat. Med. 2018, 24, 628-637. [CrossRef] [PubMed]

26. Narod, S.A.; Huzarski, T.; Gronwald, J.; Byrski, T.; Marczyk, E.; Cybulski, C.; Szwiec, M.; Wisniowski, R.; Birkenfeld, B.; Kilar, E.; et al. Predictors of survival for breast cancer patients with a BRCA1 mutation. Breast Cancer Res. Treat. 2018, 168, 513-521. [CrossRef] [PubMed]

27. Byrski, T.; Gronwald, J.; Huzarski, T.; Grzybowska, E.; Budryk, M.; Stawicka, M.; Mierzwa, T.; Szwiec, M.; Wisniowski, R.; Siolek, M.; et al. Pathologic Complete Response Rates in Young Women with BRCA1-Positive Breast Cancers after Neoadjuvant Chemotherapy. J. Clin. Oncol. 2010, 28, 375-379. [CrossRef] [PubMed]

28. Poggio, F.; Bruzzone, M.; Ceppi, M.; Pondé, N.F.; La Valle, G.; Del Mastro, L.; de Azambuja, E.; Lambertini, M. Platinum-Based Neoadjuvant Chemotherapy in Triple-Negative Breast Cancer: A Systematic Review and Meta-Analysis. Ann. Oncol. 2018, 29, 1497-1508. [CrossRef]

29. Silver, D.P.; Richardson, A.L.; Eklund, A.C.; Wang, Z.C.; Szallasi, Z.; Li, Q.; Juul, N.; Leong, C.-O.; Calogrias, D.; Buraimoh, A.; et al. Efficacy of Neoadjuvant Cisplatin in Triple-Negative Breast Cancer. J. Clin. Oncol. 2010, 28, 1145-1153. [CrossRef]

30. Von Minckwitz, G.; Schneeweiss, A.; Loibl, S.; Salat, C.; Denkert, C.; Rezai, M.; Blohmer, J.U.; Jackisch, C.; Paepke, S.; Gerber, B.; et al. Neoadjuvant Carboplatin in Patients with Triple-Negative and HER2-Positive Early Breast Cancer (GeparSixto; GBG 66): A Randomised Phase 2 Trial. Lancet Oncol. 2014, 15, 747-756. [CrossRef]

31. Schneeweiss, A.; Möbus, V.; Tesch, H.; Hanusch, C.; Denkert, C.; Lübbe, K.; Huober, J.; Klare, P.; Kümmel, S.; Untch, M.; et al. Intense Dose-Dense Epirubicin, Paclitaxel, Cyclophosphamideversus Weekly Paclitaxel, Liposomal Doxorubicin (plus Carboplatin in Triple-Negative Breast Cancer) for Neoadjuvant Treatment of High-Risk Early Breast Cancer (GeparOcto-GBG 84): A Randomised Phase III Trial. Eur. J. Cancer 2019, 106, 181-192. [CrossRef] [PubMed]

32. ESMO. Guidelines. Available online: https://www.esmo.org/guidelines (accessed on 7 April 2021).

33. NCCN Clinical Practice Guidelines in Oncology. Available online: https://www.nccn.org/professionals/physician_gls/default. aspx (accessed on 8 April 2021).

34. Kowalik, A.; Siołek, M.; Kopczyński, J.; Krawiec, K.; Kalisz, J.; Zięba, S.; Kozak-Klonowska, B.; Wypiórkiewicz, E.; Furmańczyk, J.; Nowak-Ozimek, E.; et al. BRCA1 Founder Mutations and beyond in the Polish Population: A Single-Institution BRCA1/2 next-Generation Sequencing Study. PLoS ONE 2018, 13, e0201086. [CrossRef] [PubMed]

35. Incorvaia, L.; Fanale, D.; Bono, M.; Calò, V.; Fiorino, A.; Brando, C.; Corsini, L.R.; Cutaia, S.; Cancelliere, D.; Pivetti, A.; et al. BRCA1/2 Pathogenic Variants in Triple-Negative versus Luminal-like Breast Cancers: Genotype-Phenotype Correlation in a Cohort of 531 Patients. Ther. Adv. Med. Oncol. 2020, 12, 1-19. [CrossRef] [PubMed] 